\title{
Do All Countries Follow the Same Growth Process?
}

\author{
Ann Owen* \\ Hamilton College \\ aowen@hamilton.edu \\ Julio Videras \\ Hamilton College \\ jvideras@hamilton.edu \\ Lewis Davis \\ Union College \\ davis1@union.edu
}

September 2008

Revised: May 2009

\begin{abstract}
We estimate finite-mixture models in which countries are sorted into groups based on the similarity of the conditional distributions of their growth rates. We strongly reject the hypothesis that all countries follow a common growth process in favor of a model in which there are two classes of countries, each with its own distinct growth regime. Group membership does not conform to the usual categories used to control for parameter heterogeneity such as region or income. We find strong evidence that the quality of institutions and specifically, the degree of law and order, helps to sort countries into different regimes. Once we control for institutional features of the economy, we find no evidence that geographic features such as latitude and being landlocked play a role in determining the country groupings.
\end{abstract}

JEL Codes: O11, O17

Key words: finite-mixture models, multiple equilibria, institutional quality

*198 College Hill Road, Clinton, NY, phone: 315-859-4419, fax: 315-859-4477. We are grateful for helpful comments from Oded Galor, Paul Johnson, David Weil, an Associate Editor and two anonymous referees. 


\section{Introduction}

Is there a universal growth model, a single set of equations that govern the evolution of per capita income in every country or a majority of countries? And if not, must we assume that each country's growth experience is fundamentally idiosyncratic, a position Hausmann, Rodrik and Velasco (2005:1) associate with an "attitude of nihilism" regarding the study of growth? Or is it possible to group countries in such a way that, within each group, we are able to draw inferences about their common growth experience? As these questions suggest, addressing the heterogeneity of country growth processes is of fundamental importance to the study of economic growth.

While most growth economists would agree that heterogeneity is an important consideration in empirical work, the most common methods for addressing heterogeneous growth are unsatisfactory. The practice of including regional dummy variables or country fixed effects when panel data are available controls for differences in average growth rates, but it does not allow for differences in the marginal effect of the regressors. An alternative is to identify groups of countries for which the growth process is assumed to be similar, for example, developed and developing country groups, but this approach requires we choose an a priori income threshold and it may still result in groups with countries that follow very different growth processes. This latter concern appears to underlie the common practice of partitioning developing countries into regional subgroups such as African or Latin American countries.

In contrast to these somewhat ad hoc approaches, we employ a data-driven methodology to estimate multiple growth processes. We estimate a finite-mixture model in which countries are sorted into groups based on the similarity of the conditional distributions of their growth rates. We model the distribution of growth rates as a function of variables identified as proximate determinants of growth: initial income, the rate of investment in physical capital, human capital, and the population growth rate. In addition, we use variables that describe institutional and geographic factors to improve the classification of countries into different growth regimes.

Our results are as follows. First, we strongly reject the hypothesis that the countries in our sample follow a common growth process in favor of a model in which there are two distinct growth 
regimes. Moreover, our parameter estimates differ significantly both across groups and from the estimates of a standard growth regression that assumes only one class. Second, we show that membership in a growth regime does not depend solely on categories such as income and region. Finite-mixture regression modeling improves upon the standard treatment of dividing countries by income level because it allows for parameter heterogeneity among countries with similar incomes. Finally, we show that institutional factors play a clear role in predicting membership in growth regimes, but we find no evidence that geographic features such as latitude or if a country is landlocked help to explain the groupings. For growth empirics, our results suggest a middle ground between the two extremes mentioned at the start of the paper. All countries do not follow the same growth process, but neither is each country's growth process entirely unique. Our analysis shows that countries can be grouped in a meaningful way.

Our work relates to other research that has examined the heterogeneity of the growth process with increasing methodological sophistication. In a seminal paper in this literature, Durlauf and Johnson (1995) apply regression tree analysis using output per capita and adult literacy rates to identify countries with common growth processes. Papageorgiou (2002) extends the work of Durlauf and Johnson (1995) by also exploring whether or not trade can be used as a threshold variable. More recently, Canova (2004) and Sirimaneetham and Temple (2006) have explored the existence of multiple growth regimes. Sirimaneetham and Temple (2006) use principal components analysis to generate an index of policy quality, sort economies into groups based on the value of the index, and then explore whether average growth rates vary across groups. Canova (2004) draws on Bayesian ideas to examine income levels in Europe. His technique allows for alternative means of ordering countries to form groups. He finds that using initial income as a splitting variable generates four groups of countries. Our research shares the same motivation of these papers but our methodology complements and advances the existing literature. Contrary to Durlauf and Johnson (1995), Papageorgiou (2002), Canova (2004), and Sirimaneetham and Temple (2006), we assign countries to growth regimes based on the conditional distribution of the growth rate itself rather than predetermined factors. Our method also has the advantage of assuming a regime 
structure in which the regimes are discrete and unordered (the regimes are different, but not necessarily better or faster growing).

Bloom, Canning, and Sevilla (2003) use methods more similar to ours, finding evidence that a model with two income regimes is statistically superior to a model with one regime. These authors argue that geographic variables determine the likelihood that a country is assigned to one regime or another. However, unlike our work which focuses on the conditional distribution of growth rates, Bloom et al. focus on the unconditional distribution of the level of income and do not consider the possibility of more than two regimes. Like Bloom et al., we also explore the role of geography in determining the class or regime to which a country belongs, but we find no evidence that geographic features such as latitude or being landlocked sort countries into growth regimes once the models include the quality of institutions.

Paap, Franses, and van Dijk (2005) apply latent class models to a panel of countries allowing the growth rates data to determine the number of groupings. They find that a model assuming three groupings is statistically superior to a model that assumes economies are homogeneous. In this aspect, our methodology is similar to the work by Paap, Franses, and van Dijk (2005). ${ }^{1}$ However, our paper makes three additional original contributions. First, we examine growth rates in both developed and developing economies, unlike Paap et al. who only examine growth in developing countries. Second, by examining the conditional distribution of growth rates rather than the unconditional distribution, we are able to estimate the marginal effects of growth fundamentals within regimes. For example, we identify a group of countries for which population growth is negatively related to subsequent growth and one in which it is positively related. Finally, our method allows us to test the sources of systematic heterogeneity that drive the assignment of countries to specific regimes in a way that ties our empirical results into the current growth literature.

\footnotetext{
${ }^{1}$ In addition to Paap, Franses, and van Dijk (2005), other applications of latent class models in the economics literature include Owen and Videras (2007) and Clark, Etile, Postel-Vinay, Senik, and Van der Straeten (2005). There are relatively few applications of finite mixture models in economics; see Boxall and Adamowicz (2002) and Greene and Hensher (2003).
} 
The research most closely related to our work is Alfo, Trovato and Waldmann (2008). As we do, they estimate a non-parametric random coefficients model using a panel data set of five-year growth rates. $^{2}$ These authors identify multiple growth regimes and speculate that the latent variable that defines the classes may be related to institutions. ${ }^{3}$ Our analysis takes this as a starting point. We extend the method employed by Alfo et al. by first accounting for the sources of heterogeneity across countries. We show that quality of institutions does in fact help predict the latent variable that groups countries. Second, we are able to test simultaneously the alternative hypothesis that geographic characteristics determine growth regimes (Bloom et al., 2003). Finally, because we investigate characteristics that explain country classification, the interpretation of our approach is different. Alfo et al. motivate the latent random effect because of the possibility that some fundamental variables are omitted from the growth model. In our approach, we take the basic accumulation-driven growth equation as complete, but allow the effects of factor accumulation on growth to differ based on a latent random effect which we predict with institutional and geographic features of the country. Thus, we assume that the unobservable environment in which economies grow influences growth and we predict this environment (qualitatively) with institutional and geographic characteristics.

In comparing our work to the existing growth literature more broadly, we note that an important theme in both the empirical and theoretical growth literature is the existence of multiple equilibria. ${ }^{4}$ Empirical estimation of models with multiple equilibria typically relies on using observable characteristics such as income or education levels to sort countries into regimes. Our work is related to this approach, with an important difference. Specifically, our method to sort countries into different growth regimes is probabilistic and a function of country characteristics that are often referred to as the “deeper determinants" of growth such as institutions and geography. Therefore, we believe our work

\footnotetext{
${ }^{2}$ These are random coefficient models because each class has its own set of coefficients. The models are nonparametric because the distribution of random effects is unspecified.

${ }^{3}$ Alfo, Trovato and Waldmann (2008) use a larger sample set than we do. Because we are interested in testing hypotheses about institutional quality, we need to restrict our sample only to those countries for which we have data on institutional quality. Consequently, we find fewer classes than Alfo, Trovato and Waldmann do.

${ }^{4}$ The literature on multiple equilibria in the growth process and convergence clubs is vast. Interested readers may want to see Azariadis and Stachurski (2005) for an introduction to this literature.
} 
extends this line of thinking because we are able to choose a number of country characteristics as indicators of group membership and statistically test the validity of these indicators. Furthermore, while the existence of "convergence clubs" may be a result of countries experiencing different growth processes, it does not necessarily have to be. Identifying these clubs is not the goal of our analysis. Rather, our contribution is to apply an empirical framework in which country characteristics such as quality of institutions influence the environment in which growth occurs and therefore affect the entire process of growth, determining the effects of the accumulation of factors of production.

The following section provides a theoretical framework for our results and discusses our choice of regressors and covariates. Section 3 presents our econometric approach. Section 4 describes the data. Section 5 presents our empirical findings and policy implications. Section 6 concludes.

\section{Empirical Framework}

The empirical model we estimate includes regressors that capture the proximate determinants of economic growth. Investment, education, and population growth are direct measures of the growth of productive factors. Initial income controls for transitional dynamics that occur when earlier gains are easier than later ones, either due to technical transfer or diminishing marginal returns to capital. Our estimations are based on a standard growth equation:

$$
g_{i, t}=\beta_{0}+\beta_{y} \ln \left(y_{0, i, t}\right)+\beta_{K} \ln \left(s_{i, t}\right)+\beta_{H} \ln \left(h_{i, t}\right)+\beta_{L} \ln \left(n_{i, t}+g+\delta\right)
$$

where $g_{i, t}$ is the 5 -year average growth rate of real per capita income of country $i$ in period $t, y_{0, i, t}$ is initial income in period $t, s_{i, t}$ is the average investment rate, $h_{i, t}$ is the average years of education of the labor force during the initial year of the period, $n_{i, t}$ is the average population growth rate over period $t$ for country $i, g$ is the growth rate of technology and $\delta$ is the depreciation rate. Following Mankiw, Romer and Weil (1992) we assume the annual rates of technical progress and depreciation are constant and sum to .05. The constant term captures the level of technology that enhances labor productivity. 
As Mankiw, Romer, and Weil (1992) show, this specification can be derived directly from a Cobb-Douglas production function with capital, labor and human capital as inputs. We will estimate Equation 1 with panel data. As will become clearer in Section 3, the technique that we describe below could be considered to be a non-parametric random coefficients model. The covariates we discuss below will help us to determine which countries can be grouped together. Admittedly, five-year intervals may be the minimum length of time that will allow us to comment on factors affecting longer-run growth and we urge caution in interpreting the results. We discuss some attempts at applying this method to longerterm growth rates in Section 5.

The model in Equation 1 deliberately lacks novelty. The regressors are those the augmented neoclassical model introduced by Mankiw, Romer and Weil (1992) indicate. They are also among the handful of variables Levine and Renelt (1992) identify as being robust determinants of economic growth. While neither of these papers has gone unchallenged, they have heavily influenced later growth empirics, allowing comparison of our results with other empirical work on growth.

As we explain in more detail below, we also employ covariates that are not direct determinants of growth but help to sort countries into different growth regimes. This novel feature of our estimation allows us to present empirical results that are more consistent with the idea that some variables are proximate determinants of growth, while others may be considered "deeper" determinants in that they influence the overall environment in which growth occurs (Rodrik, Subramanian, and Trebbi, 2004). In choosing our covariates, we focus on two categories of variables that play a central role in determining a country's growth process, and more particularly how it responds to capital accumulation, population growth, and the dynamics of convergence. We proceed by choosing broad categories of country characteristics (institutions and geography) that have been suggested by a large body of work and then selecting indicators within each category that capture important features of these characteristics. An advantage of our approach is that these covariates are indicators of class membership with error. In other words, our procedure recognizes that the process of assigning countries to classes is probabilistic and, as we discuss in the following section, we can estimate the error associated with our country groupings. 
As there is an immense literature related to each of our covariates, we mention only briefly some of the previous work that motivated our choice to use measures of institutional quality and geography to sort countries into growth regimes. Institutions are widely held to play a significant role in economic growth. (See, for example, Mauro (1995), Acemoglu, Johnson and Robinson (2001), Dollar and Kraay (2003) and Rodrik, Subramanian and Trebbi (2004), among others.) Democratic political institutions in particular may also affect the economics of accumulation with a central thesis in the theoretical literature on democracy and growth being that populist policies may blunt incentives to invest in physical capital as in Alesina and Rodrik (1994) and Persson and Tabellini (1994), while also potentially subsidizing the accumulation of human capital as suggested by Bourguignon and Verdier (2000) and Benabou (2000).

Geography has also played a prominent role in the growth literature. As mentioned previously, in an article closely related to ours, Bloom, Canning, and Sevilla (2003) find that countries with cool, coastal locations have relatively high income, but that hot, landlocked countries with low rainfall are more likely to be in a poverty trap. Their work follows a number of studies that have linked climate and geographic features to economic performance. (See, Bloom and Sachs (1998), Sachs and Warner (1997) and Gallup, Sachs and Mellinger (1999) as just a few examples of this previous literature.)

Because we chose these covariates based on their prominence in the growth literature, our contribution to this literature is not to propose new growth determinants-it is to empirically model their effect in a fundamentally different way. In other words, we do not model these covariates as direct determinants of growth, but as indirect determinants that influence the environment in which growth occurs and the marginal productivity of the proximate determinants of growth.

\section{Method: Finite-mixture regression model}

We use a finite-mixture approach to estimate the growth regression model in Equation 1. This approach is an application of latent class regression models to estimate a latent discrete distribution of growth regimes. Our approach has four important features. First, the observed conditional distribution of growth rates is assumed to be a mixture of two or more distributions with different means and variances. 
Second, the parameters of the growth regression are allowed to differ across regimes. Third, the distribution of the latent regimes and the parameters of the growth regression for each regime are estimated jointly. Finally, in addition to accounting for heterogeneity in the growth process, finite mixture models can explain the sources of systematic heterogeneity. In our application, we explore whether indicators of institutional quality and geography can improve the model's fit and the assignment of countries to growth regimes.

Specifically, we assume that growth processes can be classified into $M$ discrete classes (or components). Letting $T$ represent the number of repeated observations per country, $Z$ be the vector of independent variables in Equation 1, and letting $j$ indicate latent class, the probability structure for a given country is:

$$
f\left(g_{t} \mid \mathbf{z}_{t}\right)=\sum_{j=1}^{M} \pi_{j} \prod_{t=1}^{T} f\left(g_{t} \mid j, \mathbf{z}_{t}\right)
$$

where $f\left(g_{t} \mid j, \mathbf{z}_{t}\right)$ is the distribution of growth rates conditional on membership in latent class $j$ and independent variables, and we define the probability of membership in latent class $j$ as: ${ }^{5}$

$$
\pi_{j}=\frac{\exp \left(\gamma_{j 0}\right)}{1+\exp \left(\gamma_{10}\right)+\exp \left(\gamma_{20}\right)+\ldots+\exp \left(\gamma_{M-10}\right)}
$$

We extend our analysis by examining the determinants of class membership. We use variables related to the quality of institutions and geographic features as covariates that help predict class membership. Denoting the vector of $K$ covariates as $\mathbf{V}$, we can now write the probability structure for a model with covariates as:

$$
f\left(g_{t} \mid \mathbf{z}_{t}, \mathbf{v}\right)=\sum_{j=1}^{M} \pi_{j}(\mathbf{v}) \prod_{t=1}^{T} f\left(g_{t} \mid j, \mathbf{z}_{t}\right) .
$$

Now, the probability of latent-regime membership is:

\footnotetext{
${ }^{5}$ This formulation guarantees that the probability is in the unit circle and the sum of probabilities adds up to one.
} 


$$
\pi_{j}(\mathbf{v})=\frac{\exp \left(\gamma_{j 0}+\sum_{k=1}^{K} \gamma_{j k} v_{k}\right)}{1+\exp \left(\gamma_{10}+\sum_{k=1}^{K} \gamma_{1 k} v_{k}\right)+\exp \left(\gamma_{20}+\sum_{k=1}^{K} \gamma_{2 k} v_{k}\right)+\ldots+\exp \left(\gamma_{M-10}+\sum_{k=1}^{K} \gamma_{M-1 k} v_{k}\right)}
$$

This approach differs from the standard treatment in the literature because we treat the covariates as indicators of growth regimes rather than direct determinants of growth. Importantly, we sort countries into growth regimes based on the combination of these indicators rather than on the value of specific indicators. Thus, our method is not simply a substitute for including interactions of the individual indicators with the regressors.

We estimate the model via maximum likelihood. In the case of the model with covariates, maximum-likelihood estimation involves finding the estimates of the beta parameters and the vector of gamma parameters that maximize the log-likelihood function derived from the conditional probability density function in Equation 4. Assuming the error term in the growth rate equation comes from a normal distribution and adding subscript $i$ to identify countries, the log-likelihood function is:

$$
\log L=\sum_{i=1}^{I} \log f\left(g_{i t} \mid \mathbf{z}_{i t}, \mathbf{v}_{i}, \beta_{0}, \beta_{y}, \beta_{K}, \beta_{H}, \beta_{L}, \boldsymbol{\gamma}_{j k}\right)=\sum_{i=1}^{I} \log \left[\sum_{j=1}^{M} \pi_{j}(\mathbf{v}) \prod_{t=1}^{T} f\left(g_{i t} \mid j, \mathbf{z}_{i t}\right)\right],(6)
$$

where Equation 5 defines $\pi_{j}(\mathbf{v})$ and $f\left(g_{i t} \mid j, \mathbf{z}_{i t}\right)=\frac{1}{\sqrt{2 \pi \sigma_{j}^{2}}} \exp \left\{-\frac{\left(g_{i t}-\mu_{j}\right)^{2}}{\sigma_{j}^{2}}\right\}$, and $\mu_{j}$ and $\sigma_{j}^{2}$ are the mean and variance of the growth rate of the sub-population in class $j$. In the model without covariates, the log-likelihood function of the model is the same as in Equation 6 but replacing $\sum_{j=1}^{M} \pi_{j}(\mathbf{v})$ with $\sum_{j=1}^{M} \pi_{j}$ in Equation 3.

We use Latent GOLD to perform the estimation. In practice, the likelihood functions for these types of models can feature local maxima. To ensure that we obtain the global maximum, we estimate each model using 10,000 sets of starting values. Each set might result in different log-posteriors. Latent GOLD uses the best solution until convergence (Vermunt and Magidson, 2005). We repeat the process 
twice to verify we obtain the same solution. In our application, we always obtain the same log likelihood for the same estimations, making us confident that we are obtaining global maxima for the models.

We use the empirical Bayes rule to calculate country-specific posterior membership probabilities for each country $i=1, \ldots, \mathrm{N}$. The probability that country $i$ belongs to class $j$ is:

$$
\hat{\pi}\left(j \mid \mathbf{v}_{i}, g_{i}\right)=\frac{\pi_{j}\left(\mathbf{v}_{i}\right) f\left(g_{i} \mid j, \mathbf{z}_{i}\right)}{\sum_{j=1}^{M} \pi_{j}\left(\mathbf{v}_{i}\right) f\left(g_{i} \mid j, \mathbf{z}_{i}\right)}
$$

Equation 7 emphasizes a key advantage of the finite mixture approach: because all of the parameters in the likelihood function are estimated jointly, the posterior membership probabilities depend on both the value of the covariates and the distribution of growth rates.

Once we calculate the probability of class membership for each country using Equation 7, we use the empirical Bayes modal classification rule to assign countries into classes; that is, we assign each country to the class for which it has the largest posterior probability. We will implement our estimations with panel data, however, it is important to note that we restrict countries to belong to the same class in all time periods. Later, we briefly discuss an alternative in which countries may switch classes. Although for most countries the classification occurs with posterior probabilities very close to 1 , the classification is probabilistic. The quality of the classification for each country can be determined by the conditional probability of misclassification $1-\max \hat{\pi}\left(j \mid \mathbf{v}_{i}, g_{i}\right)$ and the overall misclassification rate errors by $E=\frac{\sum_{i=1}^{N} 1-\max \hat{\pi}\left(j \mid \mathbf{v}_{i}, g_{i}\right)}{N}$ (Skrondal and Rabe-Hesketh, 2004).

In practice, the number of classes is unknown to the researcher. We start with a one-class model and then estimate subsequent models that increase the number of classes by one each time. We use information criteria based on the model's log likelihood to select the model that best fits the data. We use three different information criteria to evaluate the models: the Bayesian Information Criterion (BIC), the Corrected Akaike Information Criterion (CAIC) and the Akaike Information Criterion 3 (AIC3). All three criteria are decreasing in the value of the log likelihood and increasing in the number of parameters 
estimated. Therefore, we choose the model with the lowest BIC, CAIC and AIC3. Specifically, the BIC= $-2 \mathrm{LL}+\log (\mathrm{N}) \mathrm{J}$, the $\mathrm{CAIC}=-2 \mathrm{LL}+\log (\mathrm{N}+1) \mathrm{J}, \mathrm{AIC} 3=-2 L L+3 J$ where $L L$ is the value of the $\log$ likelihood, $\mathrm{N}$ is the sample size, and $J$ is the number of parameters estimated. ${ }^{6}$ Once the model is selected, it is then possible to test for statistical significance of the regression coefficients, the differences between the regressions coefficients across classes, and the usefulness of the covariates for sorting countries into classes.

One potential problem with the estimation of finite-mixture models is that the results can be spurious if there are singularities (or near-singularities) in the likelihood function. This is more likely to happen in finite-mixture models when the number of classes is pre-specified. In this case, the maximization algorithm could identify a maximum in the likelihood function, the fit statistics would indicate a good fit, but the results would not be meaningful. One way to confirm that the solution is not spurious due to a near-singularity is to examine the error variances of the growth regressions. If they are close to zero, then this would indicate that the solution is a near-singularity in the likelihood function and the result is spurious (McLachlan and Peel, 2000). Therefore, after we choose our preferred model, we examine the estimated error variances to ensure that they are significantly different from zero.

One final issue in maximum-likelihood estimation of standard dynamic random-effects models is that the consistency of the estimates depends on the assumptions made about initial observations. Hsiao (1986) presents several cases that vary according to whether initial observations are random or fixed and unobserved characteristics influence each individual process or not. In the standard framework that Hsiao discusses the estimates are consistent if the initial observations are fixed. However, our models do not follow the standard theoretical framework. ${ }^{7}$

\footnotetext{
${ }^{6}$ The Akaike Information Criterion (AIC) can also be used to select models. It is calculated AIC $=-2 L L+2 J$, imposing a smaller penalty for additional parameters. When the model choice suggested by the AIC differs from that of the other criteria, typically the AIC indicates more classes because of the smaller penalty for additional parameters. In choosing the AIC3 over the AIC, we follow recent research that suggests the AIC3 is the better criterion to use in selecting the number of classes in a latent class or finite mixture model. See Andrews and Currim (2003) for further discussion of this issue.

${ }^{7}$ To our knowledge, there is no research that deals specifically with the issue of initial conditions for the models we estimate in this paper. Hsiao and Pesaran (2004) discuss the problem in the context of random-coefficient panel data
} 


\section{Data}

The dependent variable is the average annual growth of real GDP per capita over the 5-year periods 1970 to 1975,1975 to 1980,1980 to 1985,1985 to 1990 , and 1995 to 2000 . The independent variables are the log of real GDP per capita in the initial year of each period, the log of average annual population growth rates plus .05 , the log of average investment rates, and the log of average years of schooling of the labor force in the initial year of the five-year interval. As has been discussed by many others, growth regressions of this type are plagued by endogeneity so we must be cautious in inferring causality. Nonetheless, we use this standard specification because it allows us to focus on the issue of the heterogeneity of growth processes and makes it easier to compare our results with those of other studies.

As mentioned above, we use institutional and geographic variables as covariates to help to predict class membership. We use the absolute value of latitude to capture geographic features that are related to a country's agricultural and disease endowment and a dummy variable indicating if a country is landlocked to capture its natural degree of openness. To proxy for institutional quality, we first use European settler mortality rates. As Acemoglu, Johnson, and Robinson (2001) argue, settler mortality influenced colonization strategy and, thus, the development of growth-promoting institutions. In a second estimation we use indices of law and order and democracy to expand our sample beyond the set of European colonies. We use all the countries and all time periods for which all data are available. In the first model, without the covariates predicting class membership, we do restrict our sample only to those countries for which we have the settler mortality data so that our results are comparable. In this case, we have 265 observations from 47 countries. When we expand our sample by replacing settler mortality with indicators of current institutional quality, we have 426 observations from 74 countries. Table 1 provides descriptive statistics and the data sources.

models but they do not examine finite-mixture models. Aitkin and Alfo $(1998,2003)$ have studied finite-mixture models with binary repeated observations in a Markovian framework, but we do not model a Markov process. 


\section{Results and Discussion}

In this section we discuss the results of maximizing the log-likelihood function defined by Equation 6. As a preliminary step, we first estimate a model without covariates (but using the same sample as if we had included the covariates). Second, we estimate models that include landlocked, latitude, and settler mortality as covariates. Third, to increase our sample size, we replace settler mortality with two measures of current institutional quality. Finally, we estimate models that include time effects and regional dummies. Adding these dummy variables, in particular the regional dummies, brings up interesting conceptual questions that we discuss in detail in Section 5.1. Overall, these models are similar qualitatively and the model with time effects and regional dummies generates the most plausible marginal effects.

Table 2 presents the fit statistics for the models without covariates from one to five classes. The three information criteria, the BIC, AIC3 and the corrected AIC suggest that a two-class model best fits the data. Thus, countries in this sample experience two different growth processes. As we discussed below, this result holds for all the models we estimate. Although not shown in Table 2, we also perform a likelihood ratio test (bootstrapping the p-values) to confirm that the two-class model is preferred over the one-class model. In addition, the error variances for each class (not shown in Table 2) are also significantly different than zero, indicating that we do not have a spurious result due to a singularity in the likelihood function (McLachlan and Peel, 2000).

Next, we estimate models that include landlocked, latitude, and settler mortality as covariates. Table 3 presents the fit statistics for these models. The three information criteria point again to the two class model. ${ }^{8}$ Bootstrapped likelihood ratio tests also prefer the two class model with covariates over the one-class model with covariates. The error variances for each class continue to be significantly different than zero. Table 4 displays the coefficient estimates. The first column of Table 4 presents the one-class model and the second and third columns show the results of the two-class model. In the two-class model,

\footnotetext{
${ }^{8}$ The AIC3 for the four class model is slightly lower than it is for the two class model. Given that the BIC and the corrected AIC point to the two class model, we choose the more parsimonious model.
} 
the results for Class 1 mirror the estimates of the model that assumes homogeneity. On the other hand, the majority of the coefficients for Class 2 are statistically different from those of Class 1 , suggesting that countries follow different growth process. The Wald tests for the equality of coefficients across classes indicate that except for the coefficient on investment, all the remaining coefficients for Class 1 and Class 2 are statistically different from each other. Thus, assuming a common growth process for these countries would lead to incorrect conclusions.

In the two-class model, countries are sorted into classes based on a latent variable. What helps to predict this latent variable? The bottom half of Table 4 present the coefficient estimates for each covariate (corresponding to the gamma parameters in Equation 5). We report coefficients relative to Class 1: a positive coefficient indicates that higher values of the covariate are associated with greater probability of membership in Class 2 relative to membership in Class 1. Only settler mortality is significant, suggesting that the quality of institutions is responsible for sorting the countries into the classes. Of course, geography may affect settler mortality. When we run the model without settler mortality, the two geography variables have increased statistical significance. Landlocked predicts membership in Class 2 negatively (at the 1\% level) and latitude positively predicts Class 2 membership, though with lower significance (p-value of .14). The fact that these geography variables are no longer significant once the model includes settler mortality suggests that geography may play a role in sorting countries into growth regimes through its effect on institutional development.

Researchers use settler mortality because it is unlikely to be correlated with the error term in the growth equation. On the other hand, its use excludes countries that Europeans did not colonize. Because of this, our sample is relatively small and we might systematically omit countries that have common characteristics. This may explain why there are only nine countries in Class 2. Furthermore, the magnitude of the coefficients in Class 2 for education, $\ln (h)$, and population growth, $\ln (n+g+\delta)$, call these results into question. These coefficients imply that for countries in Class 2, a one standard deviation increase in $\ln (h)$ reduces growth by 2.74 percentage points and a one standard deviation increase in $\ln (n+g+\delta)$ reduces growth by .89 percentage points. The magnitudes of these effects are much larger 
than they are for Class 1. For countries in Class 1, a one standard deviation increase in $\ln (h)$ increases growth by .75 percentage points. Although these results show there are two growth processes, we do not believe we can rely heavily on the point estimates of these parameters because of the small size of Class 2. Therefore, we look to expand the sample by using a different set of covariates that might also proxy for institutions and geography but are available for a broader set of countries.

In order to draw accurate conclusions about country characteristics that sort countries into classes, the covariates we use should be uncorrelated with the error term in the growth model. Although there is a correlation between current quality of institutions and level of income, it may be justifiable in our context to argue that current institutional features of the economy are uncorrelated with the error term in the five-year growth model. Therefore, we replace settler mortality with two measures of current institutional quality, democracy and law and order. This almost doubles our sample size.

Using the expanded data set, we estimate models with one to five classes and display the fit statistics in Table 5. Although in this case the AIC3 indicates a three-class model, both the BIC and the corrected AIC suggest a two-class model. We choose the more parsimonious model. As before, the error variances are significantly different from zero, indicating that we have not simply identified a spurious solution. Table 6 displays class membership for the individual countries in the sample along with the predicted probabilities of membership. (Even though we use panel data, the model specification restricts countries to belong to the same class in each time period. Later, we briefly discuss an alternative approach.) A couple of points are worth noting. First, certainty of classification is high for most countries: the majority of countries are placed in their classes with high probability. Second, the countries in Class 2 do not all share the same observable characteristics such as region or income that researchers typically use to group countries. As Table 7 shows, countries in Class 2 tend to be faster growing countries, with higher values of law and order and democracy, less likely to be landlocked, and farther away from the equator. Importantly, by expanding the sample to include countries that Europeans did not colonize, we have added several countries in Class 2. A larger Class 2 emphasizes the importance of 
allowing heterogeneity in the growth process because it becomes clearer that there are more than just a few countries which do not conform to the results in Class 1 .

Regression results appear in Table 7. The regression results of Class 1 and Class 2 are different from those of the one-class model. In addition, Wald tests (Column 4 of Table 7) show that the coefficient on initial income and the coefficient on human capital are different for Class 1 and Class 2, suggesting that the effects of increased education and increased income vary by class. The estimated growth regression for Class 1 countries is consistent with a neoclassical, accumulation-driven growth process. We cannot draw the same conclusion for Class 2 countries. This regression shows a positive and significant coefficient on initial income, suggesting a lack of income convergence and the potential for multiple equilibria within this group. The negative coefficient on average years of education, on the other hand, indicates that there may be some convergence forces at work as countries with a more educated labor force grow more slowly. However, the magnitude of the estimates for both initial income and education are implausibly large. A one standard deviation increase in $\ln (h)$ produces a decrease in the annual growth rate of 4.66 percentage points and a one standard deviation increase in $\ln \left(y_{0}\right)$ produces an increase in growth of 2.32 percentage points. The fact that these two fairly large effects offset each other suggests that both initial income and the level of education may be picking up convergence effects. (The correlation between initial income and education is .77.)

As before, institutional quality seems to be the most important predictor of class membership, with law and order being a significant and positive predictor of membership in Class 2 (relative to Class 1). In contrast, the democracy index is not a significant predictor of class membership. This result parallels earlier work that found that political institutions are less important for growth than economic institutions, (e.g. Knack and Keefer, 1995).

\subsection{Additional means of controlling for heterogeneity}

So far we control for heterogeneity by estimating different coefficients for countries in different classes (and by calculating robust standard errors). To examine whether it might still be the case that 
there is unobserved heterogeneity within each class, we add time and regional dummies to our specification. Adding time dummies for each period is relatively straightforward, both statistically and conceptually. These time dummies capture responses to worldwide economic shocks. By letting the coefficients on the time dummies vary by class, we allow the responses to shocks to differ by class. Given that we show that institutional features of the economy are an important determinant of class membership, this interpretation naturally follows if institutions affect an economy's ability to adjust to shocks (e.g., Rodrik, 1999).

Adding regional dummies to the regressions in each class raises interesting statistical and conceptual questions. First, statistically, in order to estimate coefficients for each regional variable in each class there needs to be a positive probability for a country from each region to be in each class. This implicitly poses restrictions on the number of classes and the fineness with which we can define regional variables. For example, we find that even with only three regional variables (Africa, East Asia, Latin America), we are unable to estimate all the parameters of a model with more than three classes. Second, conceptually, we need to consider what these regional variables represent. To the extent that regional variables are proxies for a shared history or culture among countries in a region, it is more consistent with our approach to use these regional variables as covariates that explain class membership rather than as direct determinants of growth.

Following this line of thinking, we present results that include time dummies as independent variables in each regression and regional dummies as covariates that help to predict class membership. Table 8 presents fit statistics. The BIC and the CAIC indicate that the two-class model best fits the data, but the AIC3 (which does not penalize as much for additional parameters) indicates that model with more classes is best. As before, we choose the more parsimonious model. Error variances for each class in the two-class model (not shown in Table 8) are also significantly different than zero, indicating that the model is not a spurious solution.

The country classification based on modal probability for the two-class model appear in Table 9 with an asterisk indicating which countries have switched classes under this new specification. Although 
only four countries switch classes, the use of the regional dummies as covariates has the effect of grouping more countries from the same region together. Interestingly, the regression results in Table 10 indicate that the Latin America dummy variable is the only regional dummy that is statistically significant (at the $10 \%$ level). Consistent with our previous results, higher values of law and order predict membership in Class 2 while the other covariates are statistically insignificant. One interpretation of the weak predictive value of the regional dummy variables is that, in fact, they are proxies for the culture and history which affect growth via their effects on current institutional features of the economy. Therefore, when we allow both regional dummies and measures of institutional quality to sort countries into growth classes, the regional dummies have only weak explanatory power. ${ }^{9}$

Although we do not report the values of the time dummies in Table 10, several are significant and vary across the classes, suggesting that they are an important addition to the model that allow us to better estimate the effects of the growth fundamentals. The interpretation of the regression coefficients (Table 10) for Class 1 is essentially unchanged in this new specification. These countries follow the process described by the neoclassical growth model. The addition of time dummies and the regrouping of some countries affect the coefficients for Class 2. Now, initial income and investment appear with the signs and significance levels consistent with the neoclassical growth model (and are, in fact, not statistically different than the Class 1 coefficients). However, the coefficient on years of education is negative and the coefficient on population growth is positive. These two coefficient estimates for countries in Class 2 are consistent with the argument that countries whose growth had benefited from past increases in education slow down as they reach their steady states and education accumulation slows (Jones, 1997, 2002). Also, positive population growth in these models can be associated with faster growth when there are scale

\footnotetext{
${ }^{9}$ When we include regional dummies directly in the regression, the regional dummies are significant in explaining growth in one of the two classes, with African and Latin American countries growing slower and East Asian countries growing faster.
} 
effects in the R\&D sector-i.e., more people devoted to research generates greater advances in technology. ${ }^{10}$

In this model the magnitudes of the marginal effects are much more plausible than in the earlier models. The point estimates for Class 2 imply that a one standard deviation increase in $\ln \left(y_{0}\right), \ln (s), \ln (h)$ and $\ln (n+g+\delta)$ result in a change in the annual growth rate of $-1.45,1.28,-.85$, and .34 respectively. For Class 1, those same increases generate changes in the annual growth rates of $-1.52,1.15, .87$ and -1.07 , respectively.

In general, our results lend some support to the common practice of treating rich and poor countries separately, but they also suggest that this practice is far from perfect. Controlling for the influence of relative wealth on growth by using separate samples of rich and poor countries fails to take into account significant heterogeneity among countries at similar levels of development. Although Class 1 contains only developing countries, Class 2 contains both developed and developing countries. Interestingly, it is the developing countries in Class 1 that feature accumulation-driven growth, while we might better describe the growth process for countries in Class 2 with an endogenous growth model with scale effects in the production of technology.

\subsection{Policy Implications}

So far our analysis has mainly been descriptive. If we were to infer a causal role for either the covariates or the regressors in the growth process, policy conclusions would come at two levels. First, given the growth process for a particular country experiences, what should be the focus of growthenhancing policy in that country? For example, further investment in education might be recommended for countries in Class 1 but might not necessarily be a growth priority for countries in Class 2 .

Perhaps the more interesting policy insight is the answer to the question: What should a country do to move to a different group? Countries in Class 1 experience an average growth rate of 1.34 . The

\footnotetext{
${ }^{10}$ In Jones (2002), world research effort is modeled, however, with some frictions in the transfer of knowledge across countries the population in that country would be relevant. Jones notes that his conclusions are similar when these frictions are included in his model.
} 
typical country in Class 1 (one that has Class 1 average values of initial income, investment, human capital and population growth) would grow at 4.73 percent per year if its growth process were described by the coefficients estimated for Class 2 . The increase in growth rates associated with applying different estimates of the marginal effects of these growth fundamentals more than explains the difference in average growth rates between the two classes. Our results suggest benefits of institutional reform in developing countries. That said, although our results indicate that greater law and order is associated with a higher probability of being in Class 2, this crude measure may be a proxy for institutional quality in several respects and does not necessarily indicate a structural relationship between law and order and faster growth.

\subsection{Further Extensions}

While we use panel data looking at growth over five-year intervals, in principle we can apply our methods to data that measure growth over longer periods (cross-section regressions examining thirty- or forty-year growth rates or a shorter panel examining ten-year growth rates). However, longer term growth rates reduce the sample size and we cannot find a parsimonious model that is consistently selected by all three information criteria.

In the results we report, we examine five-year growth rates, but we constrain countries to be in the same class over the entire period. It is also possible to extend our methods to allow regime switching (countries switch classes over the period) via a Markov process. When we estimate models with this switching feature, we are unable to identify a model that fits the data better than the ones in which countries are constrained to stay in the same class. This finding is in contrast to that of Paap, Franses and van Dijk (2005) who find instability in the groupings of countries based on unconditional growth rates. The result may be different because we examine the conditional distribution of growth rates or because of our use of five-year average growth rates rather than one-year growth rates. Our covariates, which do not change or change very little over our sample period, are likely influencing our finding of stability. 
Nonetheless, such a model also fits well with the theoretical literature that addresses regime-switching and it is a fruitful area for further research.

\section{Conclusion}

This paper presents a novel application of finite mixture models for estimating growth equations. Our results suggest that countries follow more than one growth process and that the quality of institutions is an important factor that sorts countries into different regimes. An important implication of these findings is that pooled, one-class analysis that overlooks the heterogeneity in the growth process can lead to incorrect conclusions about growth in many countries.

The main contribution of our work is to present an empirical technique that matches up with the theoretical ideas that consider growth to be influenced by both proximate determinants and "deeper determinants." In our framework, country characteristics such as quality of institutions influence the environment in which growth occurs and therefore affect the entire process of growth, determining the effects of the accumulation of factors of production. 
Table 1: Descriptive Statistics

\begin{tabular}{|c|c|c|c|c|c|}
\hline Variable & Obs. & Mean & SD & Description & Data Source \\
\hline GROWTH & 426 & 1.75 & 2.84 & $\begin{array}{l}\text { Average annual growth } \\
\text { rate over } 5 \text { year period }\end{array}$ & PWT 6.2 \\
\hline $\operatorname{Ln}\left(y_{0}\right)$ & 426 & 7.85 & 1.49 & Log of initial income & PWT 6.2 \\
\hline $\operatorname{Ln}(s)$ & 426 & 2.76 & .530 & Log of investment rate & PWT 6.2 \\
\hline $\operatorname{Ln}(\mathrm{h})$ & 426 & 1.54 & .663 & $\begin{array}{l}\text { Log of initial average } \\
\text { years of education of } \\
\text { labor force }\end{array}$ & Barro and Lee data set \\
\hline $\operatorname{Ln}(n+g+\delta)$ & 426 & 1.89 & .160 & $\begin{array}{l}\text { Log of population } \\
\text { growth }+ \text { technology } \\
\text { growth }+ \text { depreciation } \\
\text { rate }\end{array}$ & $\begin{array}{c}\text { PWT 6.2, } \mathrm{g}+\delta \text { assumed to } \\
\text { be } .05\end{array}$ \\
\hline $\begin{array}{l}\text { Law and } \\
\text { Order }\end{array}$ & 426 & .621 & .240 & Index of law and order & ICRG \\
\hline Democracy & 426 & .676 & .212 & Index of democracy & ICRG \\
\hline Latitude & 426 & .296 & .192 & $\begin{array}{l}\text { Absolute value of } \\
\text { latitude }\end{array}$ & $\begin{array}{c}\text { La Porta, Lopez-de-Silanas, } \\
\text { Shleifer, Vishny (1998) }\end{array}$ \\
\hline Landlocked & 426 & .147 & .355 & $=1$ if landlocked & Author's calculations \\
\hline $\begin{array}{l}\text { Settler } \\
\text { Mortality }\end{array}$ & 265 & 4.42 & 1.10 & $\begin{array}{l}\text { Log of European settler } \\
\text { mortality }\end{array}$ & $\begin{array}{l}\text { Acemoglu, Johnson and } \\
\text { Robinson (2001) }\end{array}$ \\
\hline
\end{tabular}


Table 2: Fit Statistics for Model without Covariates

\begin{tabular}{|c|c|c|c|c|c|c|c|}
\hline & $\begin{array}{l}\text { Log } \\
\text { Likelihood }\end{array}$ & $\mathrm{BIC}$ & AIC3 & CAIC & K & $\begin{array}{l}\text { Clasification } \\
\text { Error }\end{array}$ & $\mathrm{R}^{2}$ \\
\hline $\begin{array}{l}\text { 1-Class } \\
\text { Regression }\end{array}$ & -627.289 & 1277.678 & 1272.578 & 1283.6784 & 6 & 0 & 0.139 \\
\hline $\begin{array}{l}\text { 2-Class } \\
\text { Regression }\end{array}$ & -609.505 & 1269.062 & 1258.01 & 1282.0615 & 13 & 0.0512 & 0.2127 \\
\hline $\begin{array}{l}\text { 3-Class } \\
\text { Regression }\end{array}$ & -600.417 & 1277.836 & 1260.833 & 1297.8362 & 20 & 0.0591 & 0.2363 \\
\hline $\begin{array}{l}\text { 4-Class } \\
\text { Regression }\end{array}$ & -592.935 & 1289.825 & 1266.871 & 1316.8248 & 27 & 0.0976 & 0.3045 \\
\hline $\begin{array}{l}\text { 5-Class } \\
\text { Regression }\end{array}$ & -583.625 & 1298.156 & 1269.251 & 1332.1558 & 34 & 0.0983 & 0.3484 \\
\hline
\end{tabular}

Table 3: Fit Statistics for Model using Landlocked, Latitude and Settler Mortality as Covariates

\begin{tabular}{|c|c|c|c|c|c|c|c|}
\hline & $\begin{array}{l}\text { Log } \\
\text { Likelihood }\end{array}$ & $\mathrm{BIC}$ & AIC3 & CAIC & $\mathrm{K}$ & $\begin{array}{l}\text { Classification } \\
\text { Error }\end{array}$ & $R^{2}$ \\
\hline $\begin{array}{l}\text { 1-Class } \\
\text { Regression }\end{array}$ & -627.289 & 1277.678 & 1272.578 & 1283.6784 & 6 & 0 & 0.139 \\
\hline $\begin{array}{l}\text { 2-Class } \\
\text { Regression }\end{array}$ & -601.828 & 1265.259 & 1251.657 & 1281.2592 & 16 & 0.0039 & 0.232 \\
\hline $\begin{array}{l}\text { 3-Class } \\
\text { Regression }\end{array}$ & -587.943 & 1275.99 & 1253.886 & 1301.9901 & 26 & 0.0361 & 0.2603 \\
\hline $\begin{array}{l}\text { 4-Class } \\
\text { Regression }\end{array}$ & -571.618 & 1281.842 & 1251.237 & 1317.8418 & 36 & 0.0011 & 0.2763 \\
\hline $\begin{array}{l}\text { 5-Class } \\
\text { Regression }\end{array}$ & -559.453 & 1296.012 & 1256.905 & 1342.0121 & 46 & 0.0249 & 0.3382 \\
\hline
\end{tabular}


Table 4: Growth regression results for model with covariates

\begin{tabular}{|c|c|c|c|c|}
\hline & $(1)$ & (2) & (3) & (4) \\
\hline Variable & $\begin{array}{c}\text { One Class } \\
\text { Model (OLS) }\end{array}$ & Class 1 & Class 2 & $\begin{array}{l}\mathrm{p} \text {-value for } \\
\text { Wald statistic } \\
\text { for equality of } \\
\text { coefficients } \\
\text { across classes }\end{array}$ \\
\hline $\operatorname{Ln}\left(y_{0}\right)$ & $\begin{array}{c}-.7586 * * * \\
(.2642)\end{array}$ & $\begin{array}{c}-0.8449 * * \\
(.3202)\end{array}$ & $\begin{array}{c}.079 \\
(0.1548)\end{array}$ & .01 \\
\hline $\operatorname{Ln}(\mathrm{s})$ & $\begin{array}{c}2.098 * * * \\
(.4508)\end{array}$ & $\begin{array}{c}1.7321 * * * \\
(.4105)\end{array}$ & $\begin{array}{c}1.9587 * * * \\
(0.2209)\end{array}$ & .63 \\
\hline $\operatorname{Ln}(\mathrm{h})$ & $\begin{array}{c}1.1240 * * \\
(.4500)\end{array}$ & $\begin{array}{l}1.1354 * * \\
(0.4853)\end{array}$ & $\begin{array}{c}-4.4452 * * * \\
(0.8854) \\
\end{array}$ & .00 \\
\hline $\operatorname{Ln}(n+g+\delta)$ & $\begin{array}{c}.1383 \\
(1.3673) \\
\end{array}$ & $\begin{array}{c}.2712 \\
(1.3563) \\
\end{array}$ & $\begin{array}{l}-5.5546^{*} \\
(3.2327) \\
\end{array}$ & .10 \\
\hline Constant & $\begin{array}{c}-.1106 \\
(2.9179)\end{array}$ & $\begin{array}{c}0.6645 \\
(3.0398)\end{array}$ & $\begin{array}{c}15.7242 * * * \\
(6.5369)\end{array}$ & .04 \\
\hline \multicolumn{5}{|l|}{ Covariates } \\
\hline $\begin{array}{l}\text { Settler } \\
\text { Mortality }\end{array}$ & & & $\begin{array}{c}-2.5781 * * * \\
(0.8008)\end{array}$ & \\
\hline Latitude & & & $\begin{array}{l}-1.2844 \\
(2.6111)\end{array}$ & \\
\hline Landlocked & & & $\begin{array}{l}-1.2427 \\
(1.095)\end{array}$ & \\
\hline $\mathrm{R}^{2}$ & .14 & .10 & .61 & \\
\hline $\begin{array}{l}\text { Class Size } \\
\text { (\% of } \\
\text { observations) }\end{array}$ & 1.00 & .81 & .19 & \\
\hline $\begin{array}{l}\text { Mean Growth } \\
\text { Rate }\end{array}$ & 1.23 & .84 & 3.26 & \\
\hline $\begin{array}{l}\text { Mean Settler } \\
\text { Mortality }\end{array}$ & 4.42 & 4.81 & 3.04 & \\
\hline Mean Latitude & .19 & .17 & .28 & \\
\hline $\begin{array}{l}\text { Mean } \\
\text { Landlocked }\end{array}$ & .12 & .15 & .00 & \\
\hline
\end{tabular}

All estimations include a constant. Robust standard errors are in parentheses. *significant at $10 \%$, $* *$ significant at $5 \%, * * *$ significant at $1 \%$

Coefficients for covariates are reported relative to class 1 . 
Table 5: Fit Statistics for model using Latitude, Landlocked, Democracy and Law and Order as Covariates

\begin{tabular}{|l|r|l|l|l|r|r|r|}
\hline & $\begin{array}{l}\text { Log } \\
\text { Likelihood }\end{array}$ & BIC(LL) & AIC3(LL) & CAIC(LL) & K & \multicolumn{2}{|l|}{ Classification } \\
Error & \multicolumn{1}{l|}{ R $^{2}$} \\
\hline 1-Class Regression & -1003.95 & 2033.728 & 2025.903 & 2039.728 & 6 & 0 & 0.1882 \\
\hline 2-Class Regression & $\mathbf{- 9 4 2 . 9 2 9}$ & $\mathbf{1 9 5 9 . 0 2 6}$ & $\mathbf{1 9 3 6 . 8 5 7}$ & $\mathbf{1 9 7 6 . 0 2 6}$ & $\mathbf{1 7}$ & $\mathbf{0 . 0 2 6 2}$ & $\mathbf{0 . 3 3 5 7}$ \\
\hline 3-Class Regression & -919.81 & 1960.133 & 1923.619 & 1988.133 & 28 & 0.0457 & 0.3526 \\
\hline 4-Class Regression & -904.879 & 1977.617 & 1926.758 & 2016.617 & 39 & 0.0868 & 0.4276 \\
\hline 5-Class Regression & -890.339 & 1995.882 & 1930.679 & 2045.882 & 50 & 0.0828 & 0.4516 \\
\hline
\end{tabular}


Table 6: Class Membership, Model using Landlocked, Latitude, Law and Order, Democracy

\begin{tabular}{|c|c|c|c|}
\hline Country & Probability of Class 1 & & Probability of Class 2 \\
\hline Argentina & 2 100 & Australia & 0.995 \\
\hline Bangladesh & $\approx 1$ & Austria & $\approx 1$ \\
\hline Bolivia & $\approx 1$ & Belgium & 0.999 \\
\hline Brazil & $\approx 1$ & Botswana & $\approx 1$ \\
\hline Chile & $\approx 1$ & Canada & 0.999 \\
\hline Colombia & $\approx 1$ & Switzerland & 0.999 \\
\hline Costa Rica & 0.998 & China & 0.870 \\
\hline Cyprus & 0.999 & Denmark & 0.999 \\
\hline Dominican Republic & 0.999 & Egypt & 0.992 \\
\hline Algeria & $\approx 1$ & Spain & 0.816 \\
\hline Ecuador & 1 & Finland & 0.987 \\
\hline Ghana & 1 & France & 0.996 \\
\hline Guinea-Bissau & 1 & UK & 0.989 \\
\hline Greece & 0.695 & Hungary & 0.986 \\
\hline Guatemala & $\approx 1$ & Israel & 0.761 \\
\hline Honduras & $\approx 1$ & Italy & 0.996 \\
\hline Indonesia & $\approx 1$ & Japan & 0.994 \\
\hline India & $\approx 1$ & Korea, Rep. & 0.858 \\
\hline Ireland & 0.998 & Netherlands & 0.999 \\
\hline Iran, Islamic Rep. & $\approx 1$ & Norway & 0.998 \\
\hline Jamaica & $\approx 1$ & New Zealand & 0.996 \\
\hline Jordan & $\approx 1$ & Poland & 0.866 \\
\hline Kenya & $\approx 1$ & Portugal & 0.904 \\
\hline Sri Lanka & $\approx 1$ & Singapore & 0.998 \\
\hline Mexico & 0.999 & Sweden & 0.998 \\
\hline Mali & $\approx 1$ & Uganda & 0.871 \\
\hline Malaysia & 0.518 & USA & 0.988 \\
\hline Niger & $\approx 1$ & & \\
\hline Nicaragua & $\approx 1$ & & \\
\hline Panama & $\approx 1$ & & \\
\hline Peru & $\approx 1$ & & \\
\hline Philippines & $\approx 1$ & & \\
\hline Papua New Guinea & $\approx 1$ & & \\
\hline Paraguay & $\approx 1$ & & \\
\hline Senegal & $\approx 1$ & & \\
\hline Sierra Leone & $\approx 1$ & & \\
\hline El Salvador & $\approx 1$ & & \\
\hline Thailand & $\approx 1$ & & \\
\hline Trinidad and Tobago & $\approx 1$ & & \\
\hline Tunisia & 0.999 & & \\
\hline Turkey & $\approx 1$ & & \\
\hline Tanzania & $\approx 1$ & & \\
\hline Uruguay & $\approx 1$ & & \\
\hline Venezuela & $\approx 1$ & & \\
\hline South Africa & $\approx 1$ & & \\
\hline Zambia & $\approx 1$ & & \\
\hline Zimbabwe & $\approx 1$ & & \\
\hline
\end{tabular}


Table 7: Growth regression Results for expanded sample

\begin{tabular}{|c|c|c|c|c|}
\hline & $(1)$ & $(2)$ & (3) & (4) \\
\hline Variable & $\begin{array}{c}\text { One Class } \\
\text { Model (OLS) }\end{array}$ & Class 1 & Class 2 & $\begin{array}{l}\mathrm{p} \text {-value for } \\
\text { Wald statistic } \\
\text { for equality of } \\
\text { coefficients } \\
\text { across classes }\end{array}$ \\
\hline $\operatorname{Ln}\left(y_{0}\right)$ & $\begin{array}{c}-0.5251 * * \\
(.2128)\end{array}$ & $\begin{array}{c}-1.0855 * * * \\
(.2914)\end{array}$ & $\begin{array}{c}1.5568 * * * \\
(.2021)\end{array}$ & .00 \\
\hline $\operatorname{Ln}(s)$ & $\begin{array}{c}2.4289 * * * \\
(0.4039)\end{array}$ & $\begin{array}{c}2.1251 * * * \\
(0.5845)\end{array}$ & $\begin{array}{c}1.4337 \\
(1.7876) \\
\end{array}$ & .75 \\
\hline $\operatorname{Ln}(\mathrm{h})$ & $\begin{array}{l}0.5015 \\
(.3489)\end{array}$ & $\begin{array}{c}1.2806 * * * \\
(0.4439)\end{array}$ & $\begin{array}{c}-7.0309 * * * \\
(1.7985)\end{array}$ & .00 \\
\hline $\operatorname{Ln}(n+g+\delta)$ & $\begin{array}{l}-1.3215 \\
(1.3002) \\
\end{array}$ & $\begin{array}{l}-2.9622^{*} \\
(1.7682) \\
\end{array}$ & $\begin{array}{c}-6.8274 \\
(8.6135) \\
\end{array}$ & .66 \\
\hline Constant & & $\begin{array}{l}7.6721 * * \\
(3.7793)\end{array}$ & $\begin{array}{c}11.3477 \\
(14.9745)\end{array}$ & .80 \\
\hline \multicolumn{5}{|l|}{ Covariates } \\
\hline $\begin{array}{l}\text { Law and } \\
\text { Order }\end{array}$ & & & $\begin{array}{l}10.2372 * * * \\
(3.3623)\end{array}$ & \\
\hline Democracy & & & $\begin{array}{c}0.432 \\
(3.0135)\end{array}$ & \\
\hline Latitude & & & $\begin{array}{c}-.0365 \\
(11.0145)\end{array}$ & \\
\hline Landlocked & & & $\begin{array}{l}-0.9167 \\
(1.7812)\end{array}$ & \\
\hline $\mathrm{R}^{2}$ & .19 & .15 & .70 & \\
\hline $\begin{array}{l}\text { Class Size } \\
\text { (\% of } \\
\text { observations) }\end{array}$ & 1.00 & .64 & .36 & \\
\hline $\begin{array}{l}\text { Mean Growth } \\
\text { Rate }\end{array}$ & 1.75 & 1.17 & 2.89 & \\
\hline $\begin{array}{l}\text { Mean Law } \\
\text { and Order }\end{array}$ & .62 & .48 & .86 & \\
\hline $\begin{array}{l}\text { Mean } \\
\text { Democracy }\end{array}$ & .68 & .57 & .84 & \\
\hline Mean Latitude & .30 & .20 & .46 & \\
\hline $\begin{array}{l}\text { Mean } \\
\text { Landlocked }\end{array}$ & .15 & .13 & .18 & \\
\hline
\end{tabular}

All estimations include a constant. Robust standard errors are in parentheses. *significant at $10 \%$, $* *$ significant at $5 \%, * * *$ significant at $1 \%$

Coefficients for covariates are reported relative to class 1 . 
Table 8: Fit Statistics for Model with Regional Dummies as Covariates and Time Dummies in Regression

\begin{tabular}{|c|c|c|c|c|c|c|c|}
\hline & LL & $\mathrm{BIC}(\mathrm{LL})$ & AIC3(LL) & CAIC(LL) & K & $\begin{array}{l}\text { Classification } \\
\text { Error }\end{array}$ & $\mathrm{R}^{2}$ \\
\hline 1-Class Regression & -990.747 & 2028.838 & 2014.493 & 2039.838 & 11 & 0 & 0.237 \\
\hline 2-Class Regression & -914.862 & $\mathbf{1 9 5 8 . 8 4 6}$ & 1919.724 & 1988.846 & 30 & 0.013 & 0.3663 \\
\hline 3-Class Regression & -883.177 & 1977.253 & 1913.353 & 2026.253 & 49 & 0.0321 & 0.4582 \\
\hline 4-Class Regression & -850.248 & 1993.172 & 1904.495 & 2061.172 & 68 & 0.0106 & 0.4716 \\
\hline 5-Class Regression & -825.253 & 2024.959 & 1911.505 & 2111.959 & 87 & 0.0333 & 0.593 \\
\hline
\end{tabular}


Table 9: Country Classification for Table 10 Regressions

\begin{tabular}{|c|c|c|c|}
\hline & Class 1 & & Probability of Class 2 \\
\hline Argentina & $\approx 1$ & Australia & $\approx 1$ \\
\hline Bangladesh & $\approx 1$ & Austria & $\approx 1$ \\
\hline Bolivia & $\approx 1$ & Belgium & $\approx 1$ \\
\hline Brazil & $\approx 1$ & Botswana & $\approx 1$ \\
\hline Chile & $\approx 1$ & Canada & $\approx 1$ \\
\hline China* & $\approx 1$ & Switzerland & $\approx 1$ \\
\hline Colombia & $\approx 1$ & Denmark & $\approx 1$ \\
\hline Costa Rica & $\approx 1$ & Egypt & 0.999 \\
\hline Cyprus & $\approx 1$ & Spain & 0.946 \\
\hline Dominican Republic & $\approx 1$ & Finland & $\approx 1$ \\
\hline Algeria & $\approx 1$ & France & $\approx 1$ \\
\hline Ecuador & $\approx 1$ & United Kingdom & 0.999 \\
\hline Ghana & $\approx 1$ & Greece* & 0.544 \\
\hline Guinea-Bissau & $\approx 1$ & Hungary & 0.998 \\
\hline Guatemala & $\approx 1$ & Israel & 0.837 \\
\hline Honduras & $\approx 1$ & Italy & 0.999 \\
\hline Indonesia & $\approx 1$ & Japan & 0.995 \\
\hline India & $\approx 1$ & Netherlands & $\approx 1$ \\
\hline Ireland & 0.998 & Norway & 0.997 \\
\hline Iran, Islamic Rep. & $\approx 1$ & New Zealand & 0.999 \\
\hline Jamaica & $\approx 1$ & Poland & 0.862 \\
\hline Jordan & $\approx 1$ & Portugal & 0.964 \\
\hline Kenya & $\approx 1$ & Singapore & 0.995 \\
\hline Korea, Rep.* & 0.997 & Sweden & $\approx 1$ \\
\hline Sri Lanka & $\approx 1$ & United States & 0.999 \\
\hline Mexico & $\approx 1$ & & \\
\hline Mali & $\approx 1$ & & \\
\hline Malaysia & 0.950 & & \\
\hline Niger & $\approx 1$ & & \\
\hline Nicaragua & $\approx 1$ & & \\
\hline Panama & $\approx 1$ & & \\
\hline Peru & $\approx 1$ & & \\
\hline Philippines & $\approx 1$ & & \\
\hline Papua New Guinea & $\approx 1$ & & \\
\hline Paraguay & $\approx 1$ & & \\
\hline Senegal & $\approx 1$ & & \\
\hline Sierra Leone & $\approx 1$ & & \\
\hline El Salvador & $\approx 1$ & & \\
\hline Thailand & $\approx 1$ & & \\
\hline Trinidad and Tobago & $\approx 1$ & & \\
\hline Tunisia & $\approx 1$ & & \\
\hline Turkey & $\approx 1$ & & \\
\hline Tanzania & $\approx 1$ & & \\
\hline Uganda* & .965 & & \\
\hline Uruguay & $\approx 1$ & & \\
\hline Venezuela & $\approx 1$ & & \\
\hline South Africa & $\approx 1$ & & \\
\hline Zambia & $\approx 1$ & & \\
\hline Zimbabwe & $\approx 1$ & & \\
\hline
\end{tabular}

*indicates that country is in a different grouping than that in Table 6 
Table 10: Growth regression results using regional dummies as covariates

\begin{tabular}{|c|c|c|c|c|}
\hline & (1) & (2) & (3) & (4) \\
\hline Variable & $\begin{array}{l}\text { One Class } \\
\text { Model } \\
\text { (OLS) }\end{array}$ & Class 1 & Class 2 & $\begin{array}{c}\text { p-value for } \\
\text { Wald statistic for equality of } \\
\text { coefficients across classes }\end{array}$ \\
\hline $\operatorname{Ln}\left(y_{0}\right)$ & $\begin{array}{c}-.912 * * * \\
(.277)\end{array}$ & $\begin{array}{c}-1.02 * * * \\
(.334)\end{array}$ & $\begin{array}{c}-.973 * * * \\
(.303)\end{array}$ & .92 \\
\hline $\operatorname{Ln}(s)$ & $\begin{array}{c}2.45 * * * \\
(.492)\end{array}$ & $\begin{array}{c}2.16^{* * * *} \\
(.473) \\
\end{array}$ & $\begin{array}{c}2.42 * * * \\
(.487)\end{array}$ & .69 \\
\hline $\operatorname{Ln}(h)$ & $\begin{array}{c}1.06 * * * \\
(.394)\end{array}$ & $\begin{array}{c}1.32 * * * \\
(.412)\end{array}$ & $\begin{array}{c}-1.29 * * \\
(.524)\end{array}$ & .00 \\
\hline $\operatorname{Ln}(n+g+\delta)$ & $\begin{array}{c}-3.21 * * \\
(1.56)\end{array}$ & $\begin{array}{c}-6.87 * * * \\
(2.02)\end{array}$ & $\begin{array}{l}2.18 * * \\
(1.07)\end{array}$ & .00 \\
\hline Constant & $\begin{array}{l}7.31 * \\
(3.96)\end{array}$ & $\begin{array}{c}15.85 * * * \\
(4.54)\end{array}$ & $\begin{array}{c}2.90 \\
(2.59) \\
\end{array}$ & .01 \\
\hline \multicolumn{5}{|l|}{ Covariates } \\
\hline Law and Order & & & $\begin{array}{c}12.92 * * * \\
(4.53)\end{array}$ & \\
\hline Democracy & & & $\begin{array}{c}2.42 \\
(4.81) \\
\end{array}$ & \\
\hline Latitude & & & $\begin{array}{c}.398 \\
(4.81) \\
\end{array}$ & \\
\hline Landlocked & & & $\begin{array}{c}.144 \\
(1.217) \\
\end{array}$ & \\
\hline Africa & & & $\begin{array}{c}.778 \\
(2.49) \\
\end{array}$ & \\
\hline Latin America & & & $\begin{array}{l}-3.47 * \\
(2.04) \\
\end{array}$ & \\
\hline East Asia & & & $\begin{array}{l}-1.26 \\
(1.74) \\
\end{array}$ & \\
\hline $\mathrm{R}^{2}$ & .24 & .29 & .61 & \\
\hline$\%$ of observations & 1.00 & .67 & .33 & \\
\hline Mean Growth Rate & 1.75 & 1.34 & 2.63 & \\
\hline $\begin{array}{l}\text { Mean Law and } \\
\text { Order }\end{array}$ & .62 & .48 & .89 & \\
\hline Mean Democracy & .68 & .56 & .88 & \\
\hline Mean Latitude & .30 & .20 & .48 & \\
\hline Mean Landlocked & .15 & .14 & .17 & \\
\hline
\end{tabular}

All estimations include dummy variables for time periods. Robust standard errors are in parentheses. $*$ significant at $10 \%, * *$ significant at $5 \%, * * *$ significant at $1 \%$

Coefficients for covariates are reported relative to class 1. 


\section{References}

Acemoglu, Daron, Simon Johnson and James A. Robinson, 2001, "The Colonial Origins of Comparative Development: An Empirical Investigation,” American Economic Review 91(5), 1369-1401.

Acemoglu, Daron, Simon Johnson, James A. Robinson, and Pierre Yared, 2008, "Income and Democracy" American Economic Review 98(3): 808-42.

Alesina, Alberto and Dani Rodrik, 1994, "Distributive Politics and Economic Growth," Quarterly Journal of Economics 109(2), 465-90.

Aitkin, Murray, and Marco Alfo, 1998, "Regression models for binary longitudinal responses" Statistical Modelling, Vol. 3, No. 4, 291-303.

Aitkin, Murray, and Marco Alfo, 2003, "Longitudinal analysis of repeated binary data using autoregressive and random effect modelling," Statistical Modelling, Vol. 3, No. 4, 291-303 (2003)

Alfo, Marco, Giovanni Trovato and Robert J. Waldmann, 2008, "Testing for Country Heterogeneity in Growth Models Using a Finite Mixture Aproach," Journal of Applied Econometrics 23: 487-514.

Andrews, R.L. and Currim, I.S., 2003, “A comparison of segment retention criteria for finite mixture logit models, Journal of Marketing Research, 40: 235-243.

Azariadis, Costas and John Stachurski, 2005, "Poverty Traps," in Philippe Aghion and Steven Durlauf, editors, Handbook of Economic Growth, Elsevier, 295-384.

Benabou, Roland, 2000, "Unequal Societies: Income Distribution and the Social Contract," American Economic Review 90 (1), 96-129.

Bloom, David E., David Canning and Jaypee Sevilla, 2003, "Geography and Poverty Traps," Journal of Economic Growth 8:355-78.

Bloom, D.E. and J.D. Sachs, 1998, "Geography, Demography and Growth in Africa," Brookings Papers on Economic Activity 2, 207-95.

Bourguignon, Francios and Thierry Verdier, 2000, "Oligarchy, Democracy, Inequality and Growth," Journal of Development Economics 62, 285-313.

Boxall, Peter C., and Wiktor .L. Adamowicz, 2002, "Understanding Heterogeneous Preferences in Random Utility Models: The Use of Latent Class Analysis," Environmental and Resource Economics, 23(4): 421-446.

Canova, Favio, 2004, "Testing for convergence clubs in income per capita: a predictive density approach," International Economic Review 45(1): 49-77.

Clark, A., F. Etile, F. Postel-Vinay, C. Senik and K. Van der Straeten, 2005, "Heterogeneity in reported well-being: evidence from twelve European countries," Economic Journal, 115: c118-c132.

Dollar, David and Aart Kraay, 2003, "Institutions, Trade, and Growth," Journal of Monetary Economics 50(1): 133-62. 
Durlauf, Steven N., and Paul A. Johnson, 1995, "Multiple Regimes and Cross-Country Behavior," Journal of Applied Econometrics 10, 365-384.

Gallup, J.L, J.D. Sachs, and A.D. Mellinger, 1999, "Geography and Economic Development," International Regional Science Review 22, 179-232.

Greene, William H., and David A. Hensher, 2003, "A Latent Class Model for Discrete Choice Analysis: Contrasts with Mixed Logit," Transportation Research Part B 37:681-698.

Hausmann, Ricardo, Rodrik, Dani, and Andres Velasco, 2005, “Growth Diagnostics,” Manuscript, Harvard University, March 2005.

Hisao, Cheng, 1989, Analysis of Panel Data, Econometric Society Monographs, no. 11 Cambridge; New York and Sydney: Cambridge University Press.

Hsiao, Cheng, and M. Hashem Pesaran, 2004, "Random coefficient panel data models," CESifo Working Paper No. 1233.

Jones, Charles I., 1997, “The Upcoming Slowdown in U.S. Economic Growth,” NBER Working Paper \#6284.

Jones, Charles I., 2002, "Sources of U.S. Economic Growth in a World of Ideas," American Economic Review 92(1): 220-239.

Knack, Stephen and Philip Keefer, 1995,'”nstitutions and Economic Performance: Cross-Country Tests Using Alternative Institutional Measures," Economics and Politics 7(3): 207-227.

Levine, Ross and David Renelt, 1992, "A Sensitivity Analysis of Cross-Country Growth Regressions," American Economic Review 82(4), pages 942-63.

McLachlan, Geoffrey J., and David Peel, 2000, Finite Mixture Models. (New York: John Wiley and Sons).

Mankiw, N. G., D. Romer, and D. Weil, 1992, "A contribution to the empirics of economic growth," Quarterly Journal of Economics, 107(2): 407-37.

Mauro, Paolo, 1995, “Corruption and Growth,” Quarterly Journal of Economics 110(3), 681-712.

Owen A.L. and J. Videras, 2007, "Culture and public goods: The case of religion and the voluntary provision of environmental quality," Journal of Environmental Economics and Management 54: 162180.

Paap, R., P.H. Franses, and D. van Dijk, 2005, "Does Africa grow slower than Asia, Latin America and the Middle East? Evidence from a new data-based classification method," Journal of Development Economics, 77: 553-570.

Papageorgiou, Chris, 2002, "Trade as a threshold variable for multiple regimes," Economics Letters 77:85-91.

Persson, Torsten and Guido Tabellini, 1994, "Is Inequality Harmful for Growth?" American Economic Review 84(3), 600-21. 
Rodrik, Dani, 1999, "Where Did all the Growth Go? External Shocks, Social Conflict and Growth Collapses," Journal of Economic Growth 4(4): 385-412.

Rodrik, Dani, Arvind Subramanian, and Francesco Trebbi, 2004, "Institutions Rule: The Primacy of Institutions Over Geography and Integration in Economic Development," Journal of Economic Growth, 9(2): 131-65.

Sachs, Jeffrey D. and Andrew M. Warner, 1997, "Fundamental Sources of Economic Growth," American Economic Review 87, 184-88.

Skrondal and Rabe-Hesketh, 2004, Generalized Latent Variable Modeling: Multilevel, Longitudinal, and Structural Equation Models. Chapman \& Hall/CRC, Boca Raton, Florida.

Sirimaneetham, V. and J. Temple, 2006, "Macroeconomic policy and the distribution of growth rates," University of Bristol Department of Economics Discussion Paper No. 06/584. 